\title{
Objective evaluation of the nasal mucosal secretion in COVID-19 patients with anosmia
}

\author{
Yuce Islamoglu ${ }^{1}$ (D) $\cdot$ Emin Gemcioglu ${ }^{2} \cdot$ Ihsan Ates $^{2}$ \\ Received: 9 September 2020 / Accepted: 15 October 2020 / Published online: 19 October 2020 \\ (C) Royal Academy of Medicine in Ireland 2020
}

\begin{abstract}
Background COVID-19 is a new disease caused by the SARS-CoV-2 virus. The olfactory dysfunction linked to COVID-19 is not associated with rhinorrhea but there is no objective evaluation.

Aims To evaluate nasal mucosal secretion objectively in COVID-19 patients with anosmia.

Methods Fifty-two COVID-19 patients with anosmia and 51 healthy individuals included. Anosmia was diagnosed by subjective questionnaires. Nasal Schirmer test was done to the left and the right nasal cavity separately.

Results All patients had anosmia and $82.6 \%$ had gustatory dysfunction. In group 1, the mean of the nasal Schirmer test results in the right cavity was $12.4 \mathrm{~mm}, 12.01 \mathrm{~mm}$ in the left nasal cavity. The median wetting distance (right plus left divided by two) was calculated $12.21 \mathrm{~mm}$. In group 2, the mean of the nasal Schirmer test results in the right cavity was $12.1 \mathrm{~mm}, 11.8 \mathrm{~mm}$ in the left nasal cavity. The median wetting distance (right plus left divided by two) was calculated $11.97 \mathrm{~mm}$. There was no difference between the two groups in terms of nasal schirmer.

Conclusion Olfactory dysfunction and gustatory dysfunction are the two of the unknown for this disease. We evaluated the nasal mucosa secretions in COVID-19 patients with anosmia objectively to evaluate if there is inflammation in the nasal mucosa. We found no difference between healthy individuals. According to our study, SARS-CoV-2 causes anosmia without causing nasal mucosal inflammation. Invasion of the olfactory bulb and central nervous system by SARS-CoV-2 may lead to anosmia in COVID-19, which may cause olfactory dysfunction.
\end{abstract}

Keywords Anosmia $\cdot$ COVID-19 $\cdot$ Nasal mucosa $\cdot$ Nasal Schimer test $\cdot$ SARS-CoV-2

\section{Introduction}

The acute respiratory disease caused by the SARS-CoV-2 virus was named by the World Health Organisation (WHO) as a pandemic in March 2020. The disease was named as COVID-19 (coronavirus disease 2019) [1]. COVID-19 has

Yuce Islamoglu

yuceislamoglu@gmail.com

Emin Gemcioglu

egemcioglu@gmail.com

Ihsan Ates

dr.ihsanates@hotmail.com

1 Department of Otolaryngology Head and Neck Surgery, Ankara City Hospital, Ankara, Turkey

2 Department of Internal Diseases, Ankara City Hospital, Ankara, Turkey an incubation period of 1 to 14 days, mostly ranging 37 days [2].

The most common symptoms of COVID-19 infection include fever, cough, and shortness of breath. Other symptoms are fatigue; vomiting; diarrhea; and less commonly runny nose, headache, sputum production, and hemoptysis. Loss of smell and taste are observed commonly in COVID-19 patients [3-6].

Respiratory viruses like rhinovirus, parainfluenza EpsteinBarr virus, and some coronaviruses may lead to an inflammatory reaction of the nasal mucosa. This inflammatory reaction cause rhinorrhea and olfactory dysfunction. The olfactory dysfunction linked to COVID-19 is not associated with rhinorrhea. European otolaryngologists observed severe olfactory and gustatory dysfunctions without rhinorrhea or nasal obstruction in COVID-19 patients but there is no objective evaluation [7-9].

Nasal Schirmer test is a modified Schirmer test used in evaluating the amount of nasal secretion. It is a cheap, fast, and practical test. Runny nose, nasal dryness, and normal 
nasal mucosa secretion can be evaluated objectively with the help of this test [10]. Normal mucosal secretion is the sign of normal physiology

Our aim is in our study to investigate the nasal secretion in COVID-19 patients with anosmia.

\section{Material and methods}

A prospective study was designed in our tertiary 3800 beds pandemic hospital. Ethical approval was obtained from the local ethical committee of our tertiary center. The study group comprised of 103 patients and two groups. Group 1 consists of 52 active COVID-19 patients who had acute onset anosmia. Group 2 consists of 51 healthy individuals.

COVID-19 patients who had a previous history of nasal surgery, smoking, and previous history of olfaction dysfunction were excluded from the study. Healthy individuals who had a history of nasal surgery, history of previous olfaction dysfunction, smoking, nasal polyposis, and allergic rhinitis were excluded from the study.

All 103 patients were examined by anterior rhinoscopy, and an endoscopic examination was performed using a 4$\mathrm{mm}$ rigid $0^{\circ}-30^{\circ}$ (Karl-Storz VR GmBH\&Co, Tuttlingen, Germany).

Olfactory dysfunction, taste dysfunction, and other symptoms were evaluated by subjective questionnaires.

\section{Laboratory procedures}

Schirmer test papers (ERC Saglik, Schirmer test paper, Turkiye) placed parallel on the nasal septum bilaterally which was defined by Lindemann et al. [10].

Powered air-purifying respirator $\left(3 \mathrm{M}^{\mathrm{TM}}\right.$ Versaflo ${ }^{\mathrm{TM}}$ PAPR) wearing otolaryngologist who is experienced doing nasal Schirmer test was placed the test paper carefully on the seromucous gland of the anterior septum in group 1. The same test was done to group 2 by the same otolaryngologist without wearing PAPR. Strips were removed 10 min later than the insertion. A moistened area on the strip was measured by millimeters.

\section{Statistical analysis}

Data were analyzed using the SPSS version 21.0 software program (Statistical Package for Social Sciences v.21, IBM, Chicago, IL). For a comparison of group 1 and group 2 in terms of nasal Schirmer tests, the Student $t$ test was used. $P<0.05$ was considered statistically significant.

\section{Results}

This study included 103 patients and 2 groups. Group 1 included 52 patients with acute onset anosmia who has PCR positive for SARS-CoV-2. Group 2 included 51 healthy individuals. The subjects included in the study were between the ages of 18 and 65 years. The mean age for group 1 was 42.3 (standard deviation \pm 16.00 ; min-max 19-65 years) and 40.4 (standard deviation \pm 13.4 ; min-max 18-65 years) in group 2 . There was no difference in age between the groups $(p=0.25)$.

All COVID-19 patients had anosmia and $82.6 \%$ had gustatory dysfunction. The most common symptoms in group 1 were fever $(46.1 \%)$, cough $(28.8 \%)$, headache $(28.8 \%)$, shortness of the breath (23\%), and myalgia (19.2\%). In group 1, 30 patients had COVID-19 pneumonia (57.69\%).

The most common co-morbid diseases in group 1 were hypertension (34.6\%) and diabetes mellitus (23\%).

In group 1, the mean of the nasal Schirmer test results in the right cavity was $12.4 \mathrm{~mm}, 12.01 \mathrm{~mm}$ in the left nasal cavity. The median wetting distance (right plus left divided by two) was calculated $12.21 \mathrm{~mm}$.

In group 2, the mean of the nasal Schirmer test results in the right cavity was $12.1 \mathrm{~mm}, 11.8 \mathrm{~mm}$ in the left nasal cavity. The median wetting distance (right plus left divided by two) was calculated $11.97 \mathrm{~mm}$.

There was no difference between the two groups in terms of nasal Schirmer tests in the right, left, and median values of the cavities (respectively $p=0.44, p=0.44, p=0.22$ ). (Table 1).

\section{Discussion}

The SARS-CoV-2 result in a new disease called COVID-19. No vaccine or specific treatment approved for COVID-19 so hand hygiene, social distancing, quarantine, and wearing face masks are the main points of preventing the spread of the disease $[11,12]$.

There is a lot of unknown about this disease. Olfactory dysfunction and gustatory dysfunction are the two of the unknown for this disease. Dysfunction in olfaction may appear

Table 1 Nasal Schirmer results of the study groups

\begin{tabular}{llll}
\hline Nasal Schirmer test & $\begin{array}{l}\text { Group 1 }(n=52) \\
\text { mean } \pm \text { SD }(\mathrm{mm})\end{array}$ & $\begin{array}{l}\text { Group 2 }(n=51) \\
\text { mean } \pm \text { SD }(\mathrm{mm})\end{array}$ & $p$ value \\
\hline Right cavity & $12.4 \pm 8.94$ & $12.1 \pm 5.89$ & $0.44^{\star}$ \\
Left cavity & $12.01 \pm 8.45$ & $11.8 \pm 5.13$ & $0.44^{\star}$ \\
Median (left + right/2) & $12.21 \pm 7.95$ & $11.97 \pm 4.06$ & $0.22^{\star}$ \\
\hline
\end{tabular}

${ }^{\star}$ Student $t$ test 
after, during, or before the other symptoms in COVID-19. In Europe, olfactory dysfunction ratio is higher than Asia $[4,7]$.

Post-viral olfactory dysfunction is an interesting topic. A study in 2007 showed that human coronavirus is a possible pathogen for post-viral olfactory dysfunction. They stated that nasal inflammation and obstruction after viral infections is not only the reason for olfaction dysfunction. Human coronaviruses may invade the olfactory bulb and central nervous system which may cause olfactory dysfunction [8].

In a recent study, it was found that there were no significant mucosal changes in paranasal CT imaging of the COVID-19 patients with anosmia [6].

Nasal mucosal secretions can be objectively evaluated by the nasal Schirmer test. This test can give us an objective evaluation of the mucosal secretions which let us evaluate inflammation in the nasal mucosa.

We evaluated 52 COVID-19 positive patients who had anosmia and 51 healthy individuals. We performed a nasal Schirmer test on the groups. Results were compared and we found no significant difference between the groups.

Limitations of our study were not doing objective smell tests on the COVID-19 patients, but the disease is very contagious so these tests are not recommended due to the transmission of the disease. Also, we did not perform the mucociliary test with saccharine because of the anosmia it was hard to evaluate taste in these patients.

\section{Conclusion}

This is the first study of the objective evaluation of the nasal mucosa secretions in COVID-19 patients with anosmia. We found no difference between healthy individuals. According to our study, SARS-CoV-2 causes anosmia without affecting nasal mucosa secretions. SARS-CoV-2 may invade the olfactory bulb and central nervous system which may cause olfactory dysfunction. Further studies should be required to clarify the pathogenesis of olfactory dysfunction in COVID-19.

\section{Compliance with ethical standards}

All authors contributed to the design, data collection, analysis, and final version of the study.

Ethical approval was taken from the local ethical committee. This study has not been presented at any meeting.

Conflict of interest The authors declare that they have no conflict of interest.

\section{References}

1. Zou L, Ruan F, Huang M, Liang L, Huang H, Hong Z, Yu J, Kang M, Song Y, Xia J, Guo Q, Song T, He J, Yen HL, Peiris M, Wu J (2020) SARS-CoV-2 viral load in upper respiratory specimens of infected patients. N Engl J Med 382(12):1177-1179. https://doi. org/10.1056/NEJMc2001737

2. Zhou M, Zhang X, Qu J (2020) Coronavirus disease 2019 (COVID-19): a clinical update. Front Med 14(2):126-135. https:// doi.org/10.1007/s11684-020-0767-8

3. Guan W, Ni Z, Hu Y, Liang W, Ou C, He JX, Liu L, Shan H, Lei CL, Hui DSC, du B, Li LJ, Zeng G, Yuen KY, Chen RC, Tang CL, Wang T, Chen PY, Xiang J, Li SY, Wang JL, Liang ZJ, Peng YX, Wei L, Liu Y, Hu YH, Peng P, Wang JM, Liu JY, Chen Z, Li G, Zheng ZJ, Qiu SQ, Luo J, Ye CJ, Zhu SY, Zhong NS, China Medical Treatment Expert Group for Covid-19 (2020) Clinical characteristics of coronavirus disease 2019 in China. N Engl J Med. https://doi.org/10.1056/NEJMoa2002032

4. Sayin İ, Yaşar KK, Yazici ZM (2020) Taste and smell impairment in COVID-19: an AAO-HNS anosmia reporting tool-based comparative study published online ahead of print. Otolaryngol Head Neck Surg 2020:194599820931820-194599820931479. https:// doi.org/10.1177/0194599820931820

5. Vaira LA, Salzano G, Deiana G, De Riu G (2020) Anosmia and ageusia: common findings in COVID-19 patients. Laryngoscope. https://doi.org/10.1002/lary.28692 Online ahead of print

6. Naeini AS, Karimi-Galougahi M, Raad N, Ghorbani J, Taraghi A, Haseli S, Mehrparvar G, Bakhshayeshkaram M (2020) Paranasal sinuses computed tomography findings in anosmia of COVID-19 [published online ahead of print, $2020 \mathrm{Jul}$ 3]. Am J Otolaryngol 41(6):102636. https://doi.org/10.1016/j.amjoto.2020.102636

7. Lechien JR, Chiesa-Estomba CM, De Siati DR et al (2020) Olfactory and gustatory dysfunctions as a clinical presentation of mild-to-moderate forms of the coronavirus disease (COVID-19): a multicenter European study. Eur Arch Otorhinolaryngol 277(8): 2251-2261. https://doi.org/10.1007/s00405-020-05965-1

8. Suzuki M, Saito K, Min WP, Vladau C, Toida K, Itoh H, Murakami S (2007) Identification of viruses in patients with postviral olfactory dysfunction. Laryngoscope. 117(2):272-277. https://doi.org/10. 1097/01.mlg.0000249922.37381.1e

9. van Riel D, Verdijk R, Kuiken T (2015) The olfactory nerve: a shortcut for influenza and other viral diseases into the central nervous system. J Pathol 235(2):277-287. https://doi.org/10.1002/ path.4461

10. Lindemann J, Tsakiropoulou E, Rettinger G, Gutter C, Scheithauer MO, Picavet V, Sommer F (2014) The intranasal Schirmer test: a preliminary study to quantify nasal secretion. Eur Arch Otorhinolaryngol 271(11):2963-2967. https://doi.org/10.1007/ s00405-014-2988-4

11. Guner R, Hasanoglu I, Aktas F (2020) COVID-19: prevention and control measures in community. Turk J Med Sci 50:571-577. https://doi.org/10.3906/sag-2004-146

12. Cheng VC, Wong SC, Chuang VW et al. (2020) The role of community-wide wearing of face mask for control of coronavirus disease 2019 (COVID-19) epidemic due to SARS-CoV-2. Infect. S0163-4453(20)30235-8. https://doi.org/10.1016/j.jinf.2020.04. 024. Online ahead of print

Publisher's note Springer Nature remains neutral with regard to jurisdictional claims in published maps and institutional affiliations. 